\title{
É PRECISO TRANSPARÊNCIA NO SISTEMA TARIFÁRIO E DE SUBSÍDIO DO TRANSPORTE COLETIVO
}

Coluna publicada em 9.1.2018: <https://www.conjur.com.br/2018-jan-09/contas-vistapreciso-transparencia-sistema-tarifario-transporte-coletivo $>$

Nem bem começou o ano, mal foram lavados os pratos da ceia, ainda não deu tempo de desmontar a árvore de Natal nem o presépio, e já começam a chegar as contas para pagar e os aumentos das tarifas públicas. Dizem que o ano só começa depois do Carnaval, mas isso não vale para a sanha arrecadatória do Estado. Além dos impostos, como o IPTU e o IPVA, cujos "carnês" já estão debaixo da porta, anuncia-se o aumento das tarifas públicas, e o transporte coletivo sai na frente.

As passagens de ônibus e metrô em São Paulo foram para $\mathrm{R} \$ 4,{ }^{1}$ o que, em uma megalópole que faz do transporte coletivo uma necessidade da qual não se pode abrir mão, tem um peso significativo no bolso do cidadão, que faz uso, no mais das vezes, de várias conduções para ir e voltar diariamente de casa ao trabalho. Uma tarifa que tem um viés bastante regressivo, uma vez que os mais pobres são os que, em regra, mais dependem desse serviço público nas grandes metrópoles.

É interessante notar também como as coisas mudam. Não faz muito tempo, em 2013, o aumento de 20 centavos nas passagens de ônibus levou milhares de pessoas às ruas, gerando protestos em todo o país. ${ }^{2}$

Após anunciado o aumento, pouco se falou no assunto, sem que a situação tenha se alterado significativamente.

1 “Tarifa de ônibus, trem e metrô será de R\$ 4 em 2018”. O Estado de S.Paulo, 27 de dezembro de 2017.

2 Tema abordado em No fundo, protestos envolvem questôes orçamentárias, nesta edição, p. 165168, e em Um ano depois, fica a pergunta: quem pagou a conta dos protestos de junho?, nesta edição, p. 173-176. 
E, apesar da importância social do sistema de transporte coletivo, dado o peso que representa no bolso do cidadão mais pobre, e da despesa que representa para os cofres públicos, quando estes subsidiam o serviço, como é o caso de São Paulo, os critérios para fixação das tarifas são pouco claros e transparentes.

É preciso dar mais atenção a esse tema.

O transporte foi recentemente introduzido na Constituição como um dos direitos sociais (Constituição, art. 6o $6^{\circ}$ com a redação dada pela Emenda Constitucional 90, de 2015), mas isso parece não ter feito grande diferença. Continuam sendo pagas tarifas que se reputam altas e sem a contrapartida de um transporte eficiente e confortável.

As formas de financiamento desse direito, especialmente nos casos de cidades como São Paulo, Rio de Janeiro e outras metrópoles, que envolvem vários sistemas de transporte coletivo, como ônibus, metrô, trens, vans, todos interligados entre si, e gerenciados por mais de um ente da federação, são múltiplas, complexas e de difícil compreensão. Mais um tema diretamente ligado ao Direito Financeiro que, mais do que qualquer outro, afeta diretamente o dia a dia de milhões de pessoas, é muito pouco abordado pelos estudiosos, ${ }^{3}$ representa um ponto obscuro das contas públicas e dá margem a toda sorte de desvios de recursos públicos. ${ }^{4}$

Nas grandes metrópoles, a questão federativa tem especial destaque, uma vez que há necessidade de cooperação entre os entes federados, dada a necessária conexão entre sistemas de transporte operados pelos municípios, como o transporte coletivo urbano, sistemas operados pelos estados, como trens metropolitanos e metrôs, e até mesmo a União, responsável pelos aeroportos.

A multiplicidade de formas de organização e contratação dos serviços de transporte coletivo abre um amplo leque de opções que o Direito Administrativo nos fornece, com permissões, concessões, parcerias e outras formas de contratação. ${ }^{5}$

3 Entre as exceções merece destaque a coluna de Ingo Sarlet, Direito fundamental ao transporte traz novos desafios a velhos problemas, publicada no ConJur em 25 de setembro de 2015. De qualquer forma, o aspecto financeiro, que envolve a questão das tarifas e subsídios, estranhamente parece não despertar o interesse de acadêmicos e pesquisadores.

4 Não são poucos os casos de corrupção, especialmente no âmbito dos municípios, que envolvem o financiamento do sistema de transporte coletivo. Só para citar o caso mais recente, veja-se o escândalo envolvendo o empresário Jacob Barata Filho, no Rio de Janeiro, o "Rei do Ônibus" ("Barata na prisão, o império dos transportes do Rio na berlinda". El Pais, 4 de julho de 2017; "Justiça do Rio decreta nova prisão do empresário Jacob Barata Filho". O Estado de S.Paulo, 16 de novembro de 2017).

5 O município de São Paulo, por exemplo, refere-se a elas expressamente no artigo 172 da sua Lei Orgânica: "Compete à Prefeitura planejar, organizar, implantar e executar, diretamente ou 
Uma pluralidade de instrumentos que são usados pelos diversos municípios, não havendo uniformidade quanto a isso. Em São Paulo, a evolução das formas de contratação já demonstrou ter havido várias experiências ao longo do tempo, e a regulamentação dada pela Lei municipal 13.241, de 2001, evidencia a complexidade da organização desse sistema. ${ }^{6}$ Isso sem contar as questões envolvendo a infraestrutura que se faz necessária para o funcionamento adequado e eficiente do sistema de transporte coletivo, o que evidentemente, torna o financiamento do sistema ainda mais complexo.

$\mathrm{E}$ as dificuldades para estabelecer a melhor, mais correta, justa e eficiente forma de operacionalizar a organização e remuneração do sistema é evidente, com inúmeras possibilidades, desde o estabelecimento de uma política tarifária baseada no controle pelo custo, remunerando o prestador pelos custos incorridos, acrescidos de uma remuneração como contraprestação pelos serviços; regulada por um preço máximo (price cap), que incentiva as empresas a controlar os custos; ou por meio do cálculo de uma taxa de retorno (rate-of-return), estabelecendo-se uma remuneração adequada aos ativos empregados. Todas apresentando vantagens e desvantagens sob vários aspectos, o que exige uma análise técnica profunda que permita identificar qual apresenta melhores resultados para cada situação, ${ }^{7}$ uma vez que a forma de financiamento escolhido importará em consequências para as escolhas que se fará em relação a quem e quanto se paga pelo serviço, bem como pela sua qualidade, eficiência e rapidez.

É relevante também destacar que o transporte coletivo vem sendo atualmente remunerado por tarifas, não obstante tenha características que permitem enquadrar a remuneração como tendo a natureza de taxa, uma vez que se trata de um serviço público específico, divisível e que a Constituição expressamente reconhece como tendo caráter essencial. ${ }^{8}$ Nesse sentido, foi claro Estevão Horvath em texto

sob regime de concessão, permissão, ou outras formas de contratação, bem como regulamentar, controlar e fiscalizar o transporte público, no âmbito do Município".

6 Já foi operado pela Companhia Municipal de Transportes Coletivos (CMTC), cujo serviço lhe foi outorgado em 1946; em 1995 criou-se a SPTrans, sociedade de economia mista que faz contrataçôes públicas e gerencia até hoje o sistema; a Lei 13.241/2001 prevê que os serviços do Sistema de Transporte Coletivo Urbano de Passageiros na Cidade de São Paulo serão prestados sob os regimes público e privado (art. $\left.1^{\circ}\right)$.

7 CARVALHO, André C.; CONTANI, Eduardo. Perspectivas na prestação dos serviços públicos de transporte na América Latina. In: IGLESIAS, Enrique (coord.). Os desafios da América Latina no século XXI. São Paulo: EDUSP, 2015. p. 342-343.

8 Art. 30, "V - Compete aos Municípios organizar e prestar, diretamente ou sob o regime de concessão ou permissão, os serviços públicos de interesse local, incluído o de transporte cole- 
sobre o tema, reconhecendo a consequência de ficar a cobrança sujeita ao regime jurídico próprio dos tributos, entre os quais o da estrita legalidade e da anterioridade. ${ }^{9}$ Mas não é o que vem sendo observado, como se vê expressamente na própria Lei Orgânica do Município de São Paulo, que, em seu artigo 178, estabelece que as "tarifas dos serviços públicos de transporte são de competência exclusiva do Município, e deverão ser fixadas pelo Executivo", ${ }^{10}$ cabendo-lhe enviar à Câmara Municipal, em até cinco dias úteis antes da entrada em vigor da tarifa, as planilhas e outros elementos que lhe servirão de base, divulgando amplamente para a população os critérios observados. ${ }^{11}$

Deixando de lado a discussão sobre a natureza jurídica do valor cobrado pelo serviço de transporte coletivo urbano, que extrapolaria o que se pretende abordar nesse texto, o fato é que os municípios têm o dever de proporcionar um transporte que atenda às necessidades da população, um direito constitucionalmente reconhecido, cabendo-lhe gerenciar a prestação desse serviço, mediante tarifa acessível. ${ }^{12}$

No que se refere às tarifas, não se pode esquecer a multiplicidade de formas de pagamento, que abrangem bilhetes únicos, múltiplos, integrados com outros sistemas, cobrança por tempo, por viagem, bem como os vários benefícios existentes, como gratuidades e reduções (idosos, estudantes, pessoas com deficiência, desempregados). Releva destacar que as gratuidades têm forte impacto financeiro, estimando-se que menos da metade dos usuários (47,02\%) efetivamente pagam a tarifa, e, desses, apenas cerca de $2 / 3$ de forma integral. ${ }^{13} \mathrm{E}$ há ainda outras formas de gra-

tivo, que tem caráter essencial”. A Lei Orgânica do Município de São Paulo também reconhece a essencialidade do serviço: "Art. 177. Ao operador direto não será admitida a ameaça de interrupção, nem a solução de continuidade ou deficiência grave na prestação do serviço público essencial de transporte coletivo urbano" (g.n). No mesmo sentido dispõe o art. 172, parágrafo único: "Lei disporá sobre a organização e a prestação dos serviços de transportes públicos, que têm caráter essencial”.

9 Tarifa de transporte coletivo urbano. Revista de Direito Tributário, São Paulo, Revista dos Tribunais, n. 65, 1993, p. 155.

10 E na Lei paulistana 13.241, de 2001, que no artigo 5, VI, considera a tarifa um preço público.

11 Artigo 178, parágrafo único, com a redação dada pela Emenda 7/91.

12 Lei Orgânica do Município de São Paulo, artigo 7o, III: "É dever do Poder Municipal, em cooperação com a União, o Estado e com outros Municípios, assegurar a todos o exercício dos direitos individuais, coletivos, difusos e sociais estabelecidos pela Constituição da República e pela Constituição Estadual, e daqueles inerentes às condiçóes de vida na cidade, inseridos nas competências municipais específicas, em especial no que respeita a locomoção através de transporte coletivo adequado, mediante tarifa acessível ao usuário”.

13 Ofício do Poder Executivo endereçado à Câmara Municipal justificando o reajuste da tarifa, de $1^{\circ}$ de janeiro de 2017, Quadro 4 anexo (Ofício 001/17 SMT.GAB). 
tuidade que não estão contabilizadas nos dados fornecidos pelo Poder Executivo, como bem observado no minucioso estudo de Fernando Machado, tais como menores de seis anos de idade, policiais militares, guardas-civis metropolitanos, carteiros, gestantes participantes do Programa Mãe Paulistana, oficiais de Justiça do Trabalho e conselheiros participativos municipais, ${ }^{14}$ o que torna bastante difícil calcular o exato custo de um passageiro transportado pelo sistema.

O gigantismo do sistema de transporte coletivo por ônibus na cidade de São Paulo pode ser visto em alguns números. No início do ano passado, registrava uma frota total de mais de 14 mil veículos, que rodava mais de 84 milhões de quilômetros, transportando quase 240 milhões de passageiros por mês. ${ }^{15}$

Alega-se que a sustentabilidade financeira desse sistema não tem sido possível apenas com os recursos das tarifas, exigindo subsídios do setor público, com o aporte de recursos orçamentários para complementá-lo, que, em São Paulo, consta de dotação específica no orçamento municipal ("compensações tarifárias do sistema de ônibus”) em valores extremamente expressivos, da ordem de R \$ 280 milhões por mês. ${ }^{16}$

No entanto, como já se pode notar, há ainda muita obscuridade nos cálculos e valores citados, até pela complexidade de um sistema que chega a ser confuso, fazendo com que a clareza dessas informações não seja suficientemente segura para permitir que se saiba exatamente como, quem e de que forma é financiado esse sistema de transporte coletivo. Não sabemos quem exatamente está pagando essa conta, nem quanto. Saber o justo valor da tarifa e o montante do subsídio é ainda um grande mistério. Um mistério que envolve muito dinheiro público e corrupção. $\mathrm{E}$ afeta diariamente o bolso do cidadão mais pobre.

E, curiosamente, como bem observou Lalo de Almeida, passados mais de quatro anos, parece que a reivindicação original dos protestos de 2013 permanece órfā, não demonstra ter sido incorporada pelos partidos brasileiros, e a questão do aumento do subsídio quase desapareceu da agenda. Bem lembra que há um consenso cada vez maior no urbanismo sobre o papel do transporte como direito-meio,

14 MACHADO, Fernando T. H. F. Tarifa zero para todos os usuários de ônibus no Município de São Paulo - um sonho possivel? Anais do Congresso Nacional de Transporte da ANTP, junho de 2017.

15 Conforme ofício citado.

16 Quadro 6 anexo ao Ofício 001/17 SMT.GAB - R\$ 278.399.397 mensais, correspondendo a cerca de $41 \%$ do custo total do sistema. In: Fernando Machado, Tarifa zero..., op. cit. 
que permite o acesso à educação, à cultura e ao trabalho, e já está na hora de incorporar a mobilidade urbana como um direito da cidadania. ${ }^{17}$

Para isso, é preciso ter organização e transparência no complexo sistema tarifário e de subsídio do transporte coletivo, especialmente nas grandes metrópoles, sem o que não há como conter esse foco de desperdício de recursos públicos e de corrupção. Quem sabe assim possamos começar o ano mais tranquilamente, sem sustos nem dissabores com tantos aumentos nas contas a pagar.

17 Lalo de Almeida. Redução da tarifa não é populismo. Folha de S.Paulo, 22 de julho de 2017. 